\title{
Effect of Ultrasound Cavitation on Weight Reduction for Prediabetic Obese Patients
}

\author{
JERMEEN E. YOUSEF, M.Sc.*; MAHER A. AL-KABALAWY, M.D.**; AMIRA H. DRAZ, M.D.** and \\ MANAR S. MOHAMED, M.D.*** \\ The Department of Basic Science, Faculty of Physical Therapy, Deraya* and Cairo** Universities and \\ The Department of Internal Medicine, Faculty of Physical Therapy, Deraya University***
}

\begin{abstract}
Background: Obesity has received considerable attention as a major health hazard and can be an underlying cause of many disorders such as type 2 diabetes.

Aim of Study: The purpose of present study is to investigate the effects of ultrasound cavitation on weight reduction for prediabetic obese patients.

Design: Randomized control trial design.

Subjects: Fifty patients prediabetic obese women from the out clinic of Faculty of Physical Therapy of Deraya University, Minia, Egypt. They were randomly assigned into two groups, each group twenty-five patients.

Patients and Method: Group I (control group): Twentyfive patients were received aerobic exercises and low caloric diet, three times per week for twelve weeks. Group II (experimental group): Twenty-five patients were received aerobic exercise, ultrasound cavitation and low caloric diet treatment, twice weekly ultrasound cavitation sessions for six weeks, and aerobics exercise three times per weeks for twelve weeks. (Вщ WHR, skin fold, fasting blood sugar level, post prandial blood sugar level and $\mathrm{HbA}_{1 \mathrm{c}}$ level) were measured before treatment (pre-test data), and after the completion of the treatment program, as a post-test measurement.
\end{abstract}

Results: There was a statistical significant effect of ultrasound cavitation to low calorie balanced diet and treadmill exercise on reduction in weight, Bщ WHR, skin fold, fasting blood glucose level, post prandial blood glucose level and $\mathrm{HbA}_{1 \mathrm{c}}$ level in prediabetic obese female patients.

Conclusions: Adding Ultrasound cavitation to low calorie balanced diet and treadmill exercise could be utilized as physical therapy program design for treatment to prediabetic obese female patients.

Key Words: Ultrasound cavitation-BMI-HbA ${ }_{1 c}-$ Prediabetes.

Correspondence to: Dr. Jermeen E. Abd El-Massih, The Department of Basic Science, Faculty of Physical Therapy, Deraya University

\section{Introduction}

OBESITY has received considerable attention as a major health hazard. The World Health Organization (WHO) and the National Institutes of Health $(\mathrm{NIH})$ have defined overweight as having a BMI between 25.0 and $29.9 \mathrm{~kg} / \mathrm{m} 2$ and obesity as having a (Body Mass Index) (BMI) greater than $30.0 \mathrm{~kg} / \mathrm{m} 2$. Obesity can be an underlying cause of many, disorders such as arthritis, lung disease, diabetes, hypertension, coronary artery disease, heart failure, cataracts, cancer, and even early death. The psychological effects are serious and may include depreciation of body self-image, poor quality of life and depression [1].

Obesity occurs as a result of white adipose tissue enlargement, caused by adipocyte hyperplasia and/or hypertrophy the origins of obesity and related metabolic disorders lie not only in the interaction between genes and traditional adult risk factors, such as unbalanced diet and physical inactivity, but also in the interplay between genes and the embryonic, fetal and early postnatal environment $[2,3]$

Obesity can be classified to either generalized or abdominal obesity. Most individuals with generalized obesity also have abdominal obesity. Some individuals may have abdominal obesity without generalized obesity [4]

Obesity has been a major contributor to the type 2 diabetes epidemic where nearly $80 \%$ of patients with type 2 diabetes are considered overweight or obese. Undeniably the prevention or delay of type 2 diabetes can be achieved through the adoption and maintenance of healthy lifestyle behaviors [5] 
The difference between prediabetes and diabetes is in how high the blood sugar levels are. Prediabetes is when your blood sugar (or glucose) levels are higher than normal but not high enough to be diagnosed as type 2 diabetes [6].

Pre-diabetes is the stage before diabetes mellitus and it might be associated with obesity (especially abdominal or visceral obesity), elevated cholesterol and hypertension. It is thus a metabolic disease or syndrome, and it usually involves no symptoms and only high blood sugar as the sole sign [7] .

Prediabetes is diagnosed when the fasting blood glucose is between $100 \mathrm{mg} / \mathrm{dL}$ and $125 \mathrm{mg} / \mathrm{dL}$ (5.7$6.4 \mathrm{mmol} / \mathrm{L}$ ), and when Oral Glucose Tolerance Test (the glucose two hours after eating 75 grams of glucose is between $140 \mathrm{mg} / \mathrm{dL}$ and $199 \mathrm{mg} / \mathrm{dL}$ $(7.8-11.1 \mathrm{mmol} / \mathrm{L})$, and when glycated hemoglobin level $\left(\mathrm{HbA}_{1 \mathrm{C}}\right)$ is $5.7 \%-6.4 \%$ [8]

Because of its growing prevalence; greater attention is required regarding how best to treat diabesity. Lifestyle modification, specifically changes in diet, Physical Activity (PA) and exercise is considered the cornerstone of both obesity and T2DM management [9].

Lifestyle modification, including a weight-loss goal of $5-10 \%$ of initial weight and moderate intensity physical activity for 30 minutes per day and/or vigorous-intensity physical activity 3 or more days per week for 20 or more minutes per occasion should be implemented for all obese individuals and those at risk for obesity or diabetes. Regular brisk walking may be easier to implement than vigorous physical activity. This approach has an excellent safety profile and might also be the most cost-effective intervention $[\mathbf{1 0 , 1 1 ]}$.

Many different dietary approaches may result in short term weight loss. The limitations of most diets are poor long-term compliance and weight regain. A low-fat (e.g., 25-30\% of calories from fat) diet is considered the conventional therapy for treating obesity. Altering the dietary glycemic load by reducing the total carbohydrate (bread, rice, potatoes, pasta, and sugar) content (45-50\% of energy intake) and consuming foods with a low glycemic index (fruits, and vegetables) results in greater weight loss than did a conventional lowfat diet $(25-30 \%)$ [12]

Aerobic exercise for 12 weeks is an effective method to decrease visceral fat, waist circumference, in obese subjects with T2DM even without weight loss. Frequent aerobic exercise has been shown to increase HDL-C levels by approximately $5 \%$ as early as 2 months from start of regular exercise in sedentary but otherwise healthy individuals $[\mathbf{1 3 , 1 4}]$.

Patients are now seeking alternative methods for effective reduction of localized areas of fat deposits without surgery. There are several different techniques being utilized to provide nonsurgical fat disruption such as mesotherapy, cryotherapy, and focused ultrasound therapy [15]

Ultrasound Fat Cavitation (USFC) is the method in handling obesity, especially in destroying fat and shaping a particular part of the body. As one of the non-surgical correction method, USFC is preferred at decreasing the risk of complications due to obesity $[\mathbf{1 6 , 1 7 ]}$.

The cavitation used in the field of aesthetic medicine is an innovative technique for a nonsurgical reduction of the localized fat and cellulite, Ultrasonic vibrations spread in the form of a wave in medium such as a liquid or a solid. When the particles of an elastic medium are under ultrasonic vibration, they act continuously in only one direction [18]

This phenomenon called cavitation is a very smart way to reduce fat because it is convert the fat into liquid and then is naturally eliminated with the urine when cavitation therapy is followed by lymphatic drainage. The process is faster and the drainage is very effective [19].

Therefore, this study was designed to investigate the effects of ultrasound cavitation on weight reduction for prediabetic obese patients.

\section{Patients and Methods}

This study was randomized control trial design and was conducted in the out clinic of Faculty of Physical Therapy in Deraya University Hospital, Minia, Egypt, in the period from November 2017 to March 2018.

Fifty patients prediabetic obese women were ranging between 25 to 40 years of age and their Bodies Mass Index (BMI) ranging between 30 to 39.9 were randomly assigned into two group each group twenty-five patients.

- Group I (control group): Twenty-five patients were received aerobic exercises and low caloric diet, three times per week for twelve weeks. 
- Group II (experimental group): Twenty-five patients were received aerobic exercise, ultrasound cavitation and low caloric diet treatment, twice weekly ultrasound cavitation sessions for six weeks, and aerobics exercise three times per weeks for twelve weeks. (BMI, WHR, skin fold, fasting blood sugar level, post prandial blood sugar level and $\mathrm{HbA}_{1 \mathrm{C}}$ level) were measured before treatment (pre-test data), and after the completion of the treatment program, as a posttest measurement.

\section{Statistical analysis:}

- Descriptive Statistical analysis data were represented as means \pm standard deviation of the mean (SD) of fasting blood glucose level, post prandial blood glucose level, $\mathrm{HbA}_{1 \mathrm{c}}$ level, body mass index, waist to hip ratio and skin caliper.

- Dependent variable: Within two groups.

- Independent variable: In between groups.

Statistical analysis was performed using Graph pad Prism 5 software and significant difference between groups was done by one-way ANOVA followed by Tukey-Kramar post hoc test for multiple comparisons with a value of $p \leq 0.05$ considered statistically significant.

\section{Results}

1- The changes in blood glucose, post -prandial glucose and ${ }_{H B A}{ }_{1 c}$ levels in the different studied groups:

A- Blood glucose level:

I- Within the same group: Data presented in (Table 1 ), show that there was a highly significant difference $(p<0.0001)$ in blood glucose level between pre and post subgroups in both groups. The mean values of blood glucose decreased from $(114 \pm 7.4)$ in pre-test to $(94.9 \pm 4.6)$ in post-test of group I (control group). Additionally, the blood glucose mean value decreased from (112.6 \pm $7.1)$ in pre-test to $(85.5 \pm 5.8)$ in post-test in group II (experimental group). This is illustrated in Fig. (1).

II- Between groups: Data of the present study revealed that there was a highly significant difference $(p<0.0001)$ in blood glucose level between post subgroups of the two groups (group I and group II). This was evidenced by decreasing the blood glucose mean value from $(94.9 \pm 4.6)$ in posttest in group I (control group) to $(85.5 \pm 5.8)$ in post-test in group II (experimental group). This is illustrated in (Table 1) and Fig. (1).

\section{B-Post-prandial blood glucose level:}

I- Within the same group: The results clearly demonstrated that there was a highly significant difference $(p<0.0001)$ in post-prandial blood glucose level between pre and post subgroups in both groups. The mean value of post-prandial blood glucose decreased from $(176.3 \pm 14.7)$ in pre-test to $(135 \pm 3.9)$ in post-test in group I (control group) and decreased from $(170.5 \pm 15.4)$ in pre-test to (120.9 \pm 8.9$)$ in post-test in group II (experimental group). This is illustrated in (Table 1) and Fig. (2).

II-Between groups: As shown in (Table 1) and Fig. (2), the post-prandial blood glucose results showed a highly significant differences $(p<0.0001)$ between post subgroups of the two groups (group I and group II). As the mean value decreased from $(135 \pm 3.9)$ in post-test in group I (control group) to $(120.9 \pm 8.9)$ in post-test in group II (experimental group).

\section{C- $H B A{ }_{1 c}$ level:}

I- Within the same group: As regard the HBA $1 \mathrm{c}$ level, there was a highly significant difference ( $p$ $<0.0001$ ) within pre and post subgroups of both groups as the mean value decreased from $(6.1 \pm 0.16)$ in pre-test to $(5.5 \pm 0.14)$ in post-test in group I (control group). In addition, the $\mathrm{HBA}_{1 \mathrm{c}}$ mean value decreased from $(5.9 \pm 0.15)$ in pre-test to $(5.1 \pm 0.19)$ in post-test in group II (experimental group). This is illustrated in (Table 1) and Fig. (3).

II- Between groups: Table (1) and Fig. (3) show that there was a highly significant difference $(p$ $<0.0001)$ in HBA $_{1 \mathrm{c}}$ level values between post subgroups of the two groups (group I and group II). The result demonstrated that the $\mathrm{HBA}_{1 \mathrm{c}}$ mean values decreased from $(5.5 \pm 0.14)$ in post-test of group I (control group) to $(5.1 \pm 0.19)$ in post-test of group II (experimental group).

\section{2- The anthropometrics measurements changes in BMI, skin fold and WHR in the different studied groups:}

\section{A- Body Mass Index (BMI):}

I- Within the same group: Data presented in (Table 2), show that there was a significant difference $(p<0.0001)$ between pre and post subgroups in BMI values of the two groups. The BMI mean value decreased from $(35.7 \pm 2.5)$ in pre-test to $(27.9 \pm 1.4)$ in post-test in group I (control group). In addition, the BMI mean value decreased from $(34.9 \pm 2.8)$ in pre-test to $(25.6 \pm 1.8)$ in post-test in group II (experimental group) as shown Fig. (4).

II-Between the groups: The present result also revealed that there was a highly significant differ- 
ence $(p<0.0001)$ in BMI values between post subgroups of the two groups (group I and group II). As the mean value decreased from $(27.9 \pm 1.4)$ in post-test in group I (control group) to $(25.6 \pm 1.8)$ in post-test in group II (experimental group). This is illustrated in (Table 2) and Fig. (4).

\section{B- Skin fold changes:}

I- Within the same group: As regard the skin fold changes, the present result clearly demonstrated that there was highly a significant difference ( $p$ $<0.0001$ ) within pre and post subgroups of the two groups. The skin fold mean value decreased from $(2.8 \pm 0.24)$ in pre-test to $(2.3 \pm 0.11)$ in post-test in group I (control group) and decreased from (2.8 \pm $0.21)$ in pre-test to $(1.9 \pm 0.23)$ in post-test in group II (experimental group). This is illustrated in (Table 2) and Fig. (5).

II- Between the groups: In addition, (Table 2) and Fig. (5) show that there was a highly significant difference $(p<0.0001)$ in skin fold values between post subgroups of the two groups (group I and group II). The skin fold mean value decreased from
(2.3 \pm 0.11$)$ in post-test in group I (control group) to $(1.9 \pm 0.23)$ in post-test in group II (experimental group).

\section{C- Waist Hip Ratio (WHR):}

I- Within the same group: The results clearly demonstrated that there was a highly significant difference $(p<0.0001)$ in WHR values within pre and post subgroups as the mean value decreased from $(0.92 \pm 0.015)$ in pre-test to $(0.86 \pm 0.026)$ in post-test in group I (control group). In addition, the WHR mean value decreased from $(0.92 \pm 0.015)$ in pre-test to $(0.82 \pm 0.027)$ in post-test in group II (experimental group). This is illustrated in (Table 2) and Fig. (6).

II-Between the groups: In addition, the present results revealed that there was a highly significant difference $(p<0.0001)$ between post subgroups in WHR values of the two groups (group I and group II) as the mean value decreased from $(0.86 \pm 0.026)$ in post-test in group I (control group) to (0.82 \pm 0.027 ) in post-test in group II (experimental group). This is illustrated in (Table 2) and Fig. (6).

Table (1): Changes in blood glucose, postprandial glucose and HBA $_{1 \mathrm{c}}$ levels in the different studied groups.

\begin{tabular}{llccc}
\hline \multirow{2}{*}{ Groups } & \multicolumn{2}{c}{ Group I } & \multicolumn{2}{c}{ Group II } \\
\cline { 2 - 5 } Parameters & \multicolumn{1}{c}{ Pre } & Post & Pre & Post \\
\hline Fasting blood glucose level (mg/dl) & $114 \pm 7.4$ & $94.9 \pm 4.6^{\mathbf{a}}$ & $112.6 \pm 7.1$ & $85.5 \pm 5.8^{\mathbf{a b}}$ \\
Post-prandial blood glucose level (mg/dl) & $176.3 \pm 14.7$ & $135 \pm 3.9 \mathbf{a}$ & $170.5 \pm 15.4$ & $120.9 \pm 8.9^{\mathbf{a b}}$ \\
HBA $_{1 \mathrm{~b}}$ & $6.1 \pm 0.16$ & $5.5 \pm 0.14 \mathbf{a}$ & $5.9 \pm 0.15$ & $5.1 \pm 0.19^{\mathbf{a b}}$ \\
\hline
\end{tabular}

Data are expressed as mean \pm S.D of 25 patients in each group.

a: Significant post from pre in the same group.

b: Significant post group II from post group I, $p \leq 0.05$.

Table (2): The mean values and standards deviations of anthropometrics measurements changes in BMI, skin fold and WHR in the different studied groups.

\begin{tabular}{lcccc}
\hline \multirow{2}{*}{ Parameters } & \multicolumn{2}{c}{ Groups } & \multicolumn{3}{c}{ Group II } \\
\cline { 2 - 5 } & Pre & Post & Pre & Post \\
\hline BMI & $35.7 \pm 2.5$ & $27.9 \pm 1.4 \mathbf{a}$ & $34.9 \pm 2.8$ & $25.6 \pm 1.8 \mathbf{a b}$ \\
Skin fold & $2.8 \pm 0.24$ & $2.3 \pm 0.11 \mathbf{a}$ & $2.8 \pm 0.21$ & $1.9 \pm 0.23 \mathbf{a b}$ \\
WHR & $0.92 \pm 0.015$ & $0.86 \pm 0.026^{\mathbf{a}}$ & $0.92 \pm 0.015$ & $0.82 \pm 0.027 \mathbf{a b}$ \\
\hline
\end{tabular}

Data are expressed as mean \pm S.D of 25 patients in each group.

a : Significant post from pre in the same group.

b : Significant post group II from post group I, $p \leq 0.05$

BMI : Body Mass Index.

WHR: Waist Hip Ratio. 


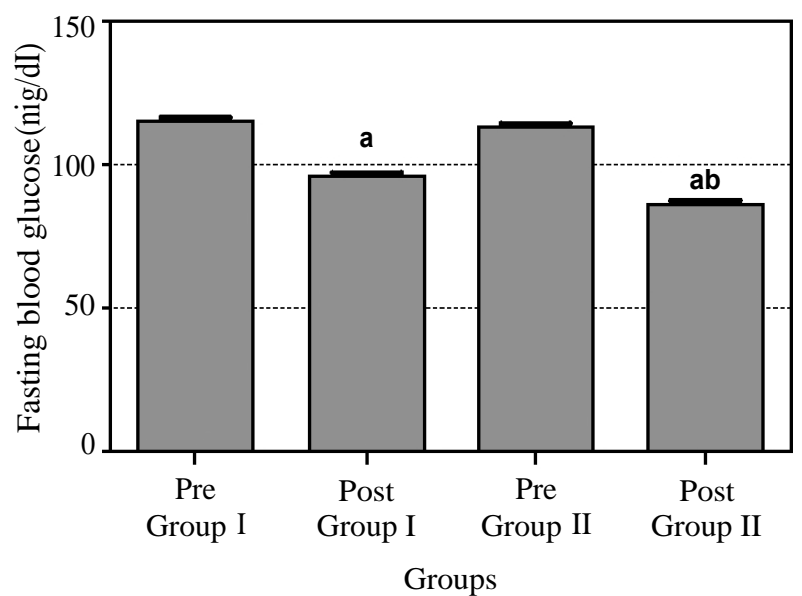

Fig. (1): Fasting blood glucose level in the different studied groups.

Data are expressed as mean \pm S.D of 25 patients in each group.

a: Significant post from pre in the same group.

b: Significant post group II from post group I, $p \leq 0.05$.

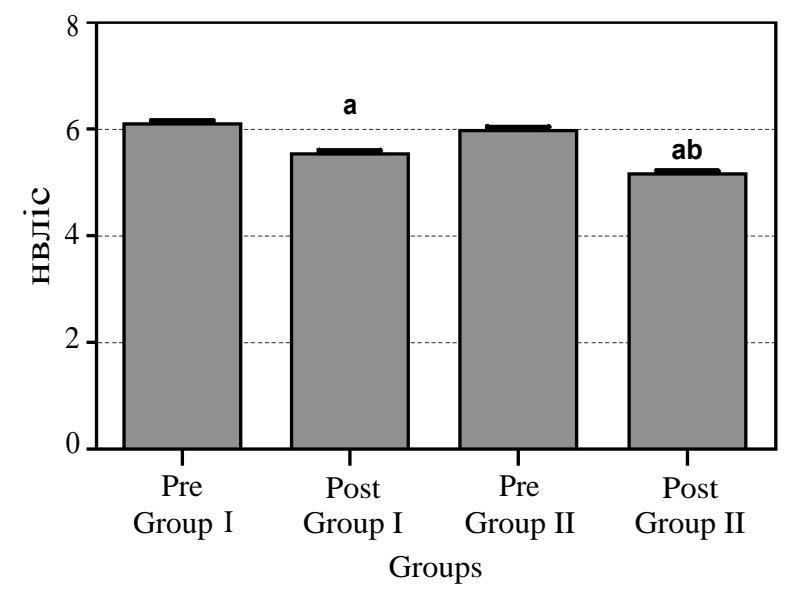

Fig. (3): HBA $_{1 \mathrm{c}}$ level in the different studied groups.

Data are expressed as mean \pm S.D of 25 patients in each group.

a: Significant post from pre in the same group.

b: Significant post group II from post group I, $p \leq 0.05$.

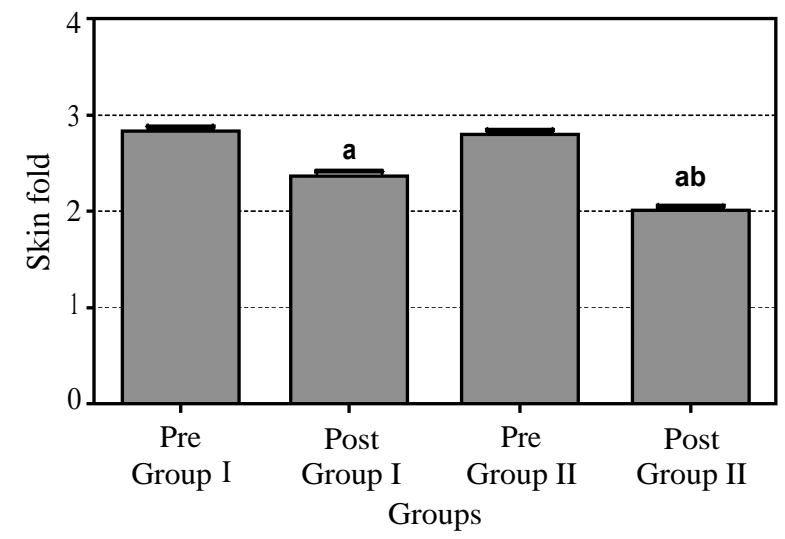

Fig. (5): Skin fold measurements in the different studied groups.

Data are expressed as mean \pm S.D of 25 patients in each group.

a: Significant post from pre in the same group.

b: Significant post group II from post group I, $p \leq 0.05$.

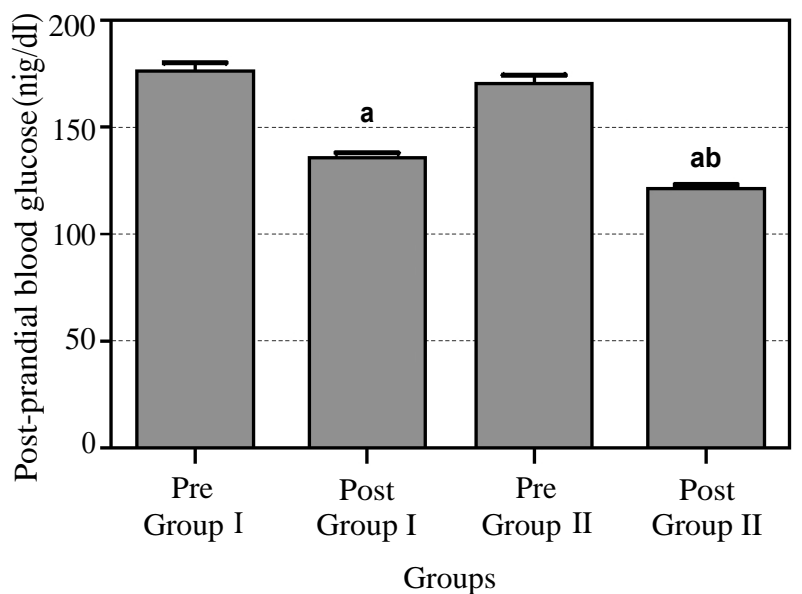

Fig. (2): Postprandial blood glucose level in the different studied groups.

Data are expressed as mean \pm S.D of 25 patients in each group.

a: Significant post from pre in the same group.

b: Significant post group II from post group I, $p \leq 0.05$.

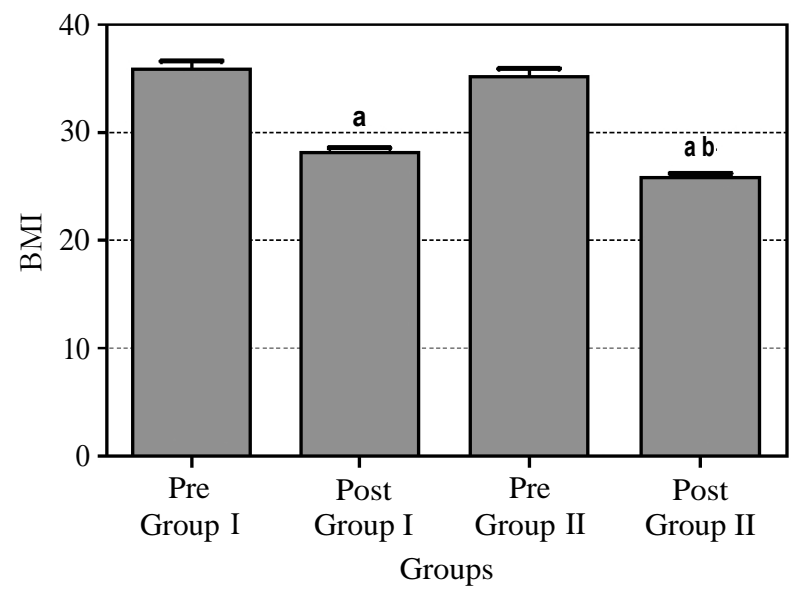

Fig. (4): BMI in the different studied groups.

Data are expressed as mean \pm S.D of 25 patients in each group. a : Significant post from pre in the same group.

b : Significant post group II from post group I, $p \leq 0.05$. BMI : Body Mass Index.

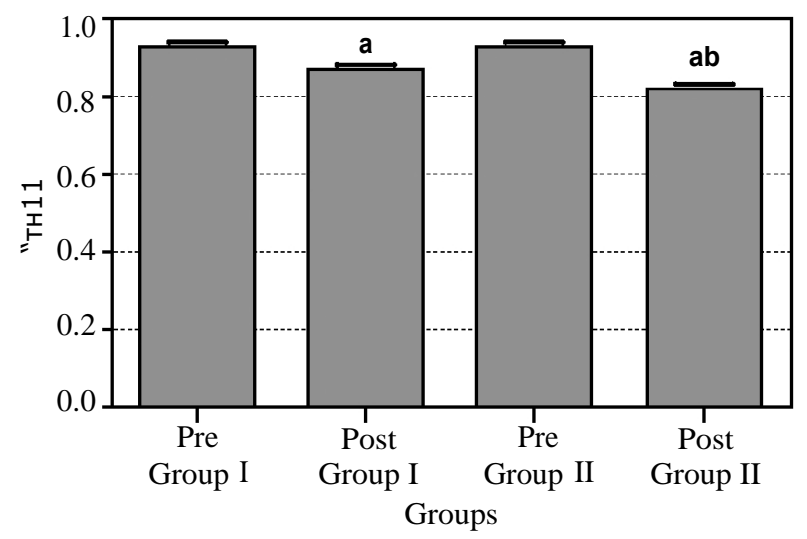

Fig. (6): WHR changes in the different studied groups.

Data are expressed as mean \pm S.D of 25 patients in each group.

a : Significant post from pre in the same group.

b : Significant post group II from post group I, $p \leq 0.05$.

WHR : Waist Hip Ratio. 


\section{Discussion}

This study was designed as a randomized control clinical trial design. The aim of this study was to determine the effectiveness of cavitation ultrasound therapy on weight reduction in prediabetic obese patients. Fifty prediabetic obese patients from both sex participated in the present study and all were assessed before and after treatment.

Mechanism eliminating the fat destruction through the ultrasound produce bubble in the tissue where the fat cells are applied, the bubble expands and then it is immediately compressed, then temperature increase due to the pressure sudden variation and the bubble implodes [15]

The implosion damages the fat cell, reducing the localized adiposity with the cavitation the fat cells are exposed to a pressure that breaks their membrane, unleashing the destruction of adipose fat deposits the fat contained (triglycerides) fragments into di glycerides is dispersed into the interstitial fluid among the cells and then cleared via the lymphatic system and transported through the vascular system to the liver. Where, fat metabolized by the lipase enzyme into glycerol and free fatty acids, Glycerol is phosphorylated and transported through the vascular system [20,21].

The 3-free fatty acids are bound to each albumin molecule and transported to the liver. Fat metabolites were processed in the liver in the same manner as fat originating from digested fat. Therefore, the liver makes no distinction between fat coming from the cavitation and fat originating from consumed food both are expelled via the urinary system [19]

Obese women with a high accumulation of visceral adipose tissue tend to have hyper triglyceridemia and low concentration of high density lioprotien cholesterol. Furthermore, the reduction in plasma concentration of high density lioprotien cholesterol in these viscerally obese women is a major factor responsible for the increase in their ratio of cholesterol [22]. Obesity, particularly with central fat distribution being a powerful predictor of risk of coronary heart disease and mortality are directly related in middle-aged women. Many studies have shown that women in their midlife tend to gain weight, with a shift to visceral fat distribution [23]

This study was designed to determine the effectiveness of cavitation ultrasound therapy, low caloric diet and exercises in reducing the body weight and visceral adiposity among prediabetic obese women.
The results of the current study are in agreement with Brown et al. [15], who studied the physics of focused external ultrasound using the and attempted to validate its efficacy in a porcine model. Gross and histologic evaluations of porcine adipose tissue after treatment with the device confirmed cavitation induced zones of injury in the adipose tissue with sparing of nervous and vascular structures as well as skin.

Our results corroborate those from MorenoMoraga et al., [21] who conducted a prospective study in Spain involved 30 patients. Each patient underwent three treatments at 1-month intervals. Areas treated were the abdomen, inner and outer thighs, flanks, inner knees, and male breasts. Ultrasound measurements and circumference measurements were used to assess changes in fat thickness. They found that the mean reduction in fat thickness after 3 treatments was 2.28 to $0.80 \mathrm{~cm}$, whereas the circumference was reduced by a mean of 3.95 to $1.99 \mathrm{~cm}$. No significant changes in weight were identified to suggest changes as secondary to weight loss. Serum triglyceride levels and liver ultrasound evaluations for steatosis were also, performed for safety profiles, all of which showed no significant abnormalities. The group reports treating more than 400 patients outside of the clinical study with successful reduction in localized adiposity and great patient satisfaction.

The results of cavitation ultrasound therapy group came in agree with Teitelbaum et al., [24] who performed a multicenter study ( 2 centers in the United States, 1 in the United Kingdom, 2 in Japan) involving 164 patients, 137 of whom had undergone a single treatment of focused external ultrasound lipolysis, whereas 27 served as controls. Follow-up was performed on days 1, 3, 7, 14, 28, 56 and 84 . They reported a single contour treatment produced a mean reduction of approximately $2 \mathrm{~cm}$ in treatment area circumference and approximately $2.9 \mathrm{~mm}$ in skin fat thickness. No adverse effect was noted on lipid profiles or liver sonography. Complications were mild and included erythema, mild blistering in 2 patients, and mild dermal erosion in 1 patient that resolved by the end of the followup period.

The obtained results disagree with Shek et al., [25] who attempted to validate the results of prior studies in the Asian population, but found strikingly different results. Fifty-three patients had up to three treatments 1 month apart. Efficacy was assessed by changes in abdominal circumference, ultrasound fat thickness, and caliper fat thickness. A patient questionnaire was also used to assess 
satisfaction. Weight loss-induced measurements were also monitored. Shek et al., [25] found that here were no significant changes in any of the measurements before and after treatment. Patients satisfaction was also poor, because results were suboptimal. Shek et al., [25] attribute the discrepancy in results to body frame size of Southern Asians compared with Caucasians, suggesting that a modification in the transducer may alleviate the difficulties in delivery of ultrasonic energy on a smaller body habitus.

Regarding the results of anthropometric variables. The weight loss decrease in BMI in this study after low caloric diet may attributed to several mechanisms including, the diuriesis and depletion in stored glycogen and reduction in fat mass the depletion of fat depot caused by hydrolysis and clearance of triglyceride stored in adipose tissue into glycerol and Free Fatty Acid (FFA) by the action of Lipoprotein Lipase (LPL) [26].

Results of previous studies showed that more than a $10 \%$ reduction in body weight in a three months' period of diet regimen [27].

Other studies have reported similar weight losses in the range of 10 to $13 \mathrm{~kg}$ in obese women undergoing 16 weeks' diet programs [28] and it was also reported that significant body weight losses, $14.5 \%$ compared to baseline over 16 -week diet regimen [23].

Also, the decrement in waist circumference and waist hip ratio may be explained by decrement in body fat mass in the abdominal region. It may also be related to regional change in LPL activity in the abdominal fat area. This lead to mobilization of FFA from centrally distributed adipose tissue [20]

This is in agreement with Teresa Kulie et al., [29], showed that the risk of Diabetes Mellitus (DM) increases with the degree and duration of being overweight or obese and with a more central or visceral distribution of body fat. Increased visceral fat enhances the degree of insulin resistance associated with obesity. In turn, insulin resistance and increased visceral fat are the hallmarks of metabolic syndrome, an assembly of risk factors for developing diabetes and cardiovascular disease.

The results of the current study are also supported by Scott et al., [30].

Abdominal obesity especially correlates with metabolic risk factors. Excess adipose tissue releases several products that apparently exacerbate these risk factors. They include Non-Esterified Fatty Acids (NEFA), cytokine, PAI-1, and adiponectin. A high plasma NEFA level overloads muscle and liver with lipid, which enhances insulin resistance. High CRP levels accompanying obesity may signify cytokine excess and a pro-inflammatory state. An elevated PAI-1 contributes to a prothrombotic state, whereas low adiponectin levels that accompany obesity correlate with worsening of metabolic risk factors. The strong connection between obesity (especially abdominal obesity) and risk factors led ATP III to define the metabolic syndrome essentially as a clustering of metabolic complications of obesity.

Also Bray [31] found that the enlarged fat cells produce the clinical problems associated with obesity either because of the weight or mass of the extra fat or because of the increased secretion of free fatty acids and numerous peptides from enlarged fat cells. The consequence of these two mechanisms is other diseases, such as diabetes mellitus.

This study demonstrated that there was a statistical significant reduction in weight, BMI, WHR, skin fold, fasting blood sugar level, post prandial blood sugar level and $\mathrm{HbA}_{1 \mathrm{C}}$ level in prediabetic obese women in group II than in group I. SO, low calorie balanced diet and treadmill exercise an effective method for prediabetic obese women management. But adding ultrasound cavitation therapy to low calorie balanced diet and treadmill exercise was more effective for management and acts as a wonderful drug in treating prediabetic obese women.

\section{Recommendations for future research:}

The following studies might be recommended:

1- Further studies can be done with larger sample size of patients.

2- Ultrasound cavitation therapy can be done on another region in the body.

3- Ultrasound cavitation therapy, low calorie balanced diet and treadmill exercise can be done on males' patients.

\section{References}

1- RERKSUPPAPHOL L. and RERKSUPPAPHOL S.: Efficacy of transcutaneous electrical acupoint stimulation compared to electroacupuncture at the main acupoints for weight reduction in obese Thai women, CR-IPHM, 3 (11): 811-20, 2011

2- TAYLOR P.D. and POSTON L.: Developmental programming of obesity in mammals. Exp. Physiol., 92 (2): 287 98, 2007. 
3- INADERA H.: The usefulness of circulating adipokine levels for the assessment of obesity-related health problems. International Journal of Medical Sciences, 5 (5): 248-62, 2008.

4- WEINSIER R.L., NAGY T.R., HUNTER G.R., DARNELL B.E., HENSRUD D.D. and WEISS H.L.: Do adaptive changes in metabolic rate favor weight regain in weightreduced individuals? An examination of the set-point theory. Am. J. Clin. Nutr., 72: 1088-94, 2000.

5- WANDER P.L., BOYKO E.J., LEONETTI D.L., et al.: Change in visceral adiposity independently predicts a greater risk of developing type 2 diabetes over 10 years in Japanese Americans. DC. 36 (2): 289-93, 2012.

6- American Diabetes Association. Standards of medical care in diabetes. Diabetes Care, 39 (1): 1-112, 2016.

7- American Diabetes Association: Classification and diagnosis of diabetes, Diabetes Care, 40 (1): 11-24, 2017.

8- Centers for Disease Control and Prevention. Diabetes Report Card, 2014, Atlanta, GA: Centers for Disease Control and Prevention, US Dept. of Health and Human Services, 2015.

9- HILLS A.P. and BYRNE N.M.: State of the science: A focus on physical activity. Asia Pac. J. Clin. Nutr., 15; 40-8, 2006.

10- CRANDALL J.P., KNOWLER W.C., KAHN S.E., MARRERO D., FLOREZ J.C., BRAY G.A., HAFFNER S.M., HOSKIN M. and NATHAN D.M.: The prevention of type 2 diabetes. Nat. Clin. Pract. Endocrinol. Metab., 4 (7): 382-93, 2008.

11- KRISHNAN S., ROSENBERG L. and PALMER J.R. : Physical activity and television watching in relation to risk of type 2 diabetes; the black women's health study. Am. J. Epidemiol., 169: 428-34, 2009.

12- KNOWLER W.C., BARRETT-CONNOR E. and FOWLER S.E. : Reduction in the incidence of type 2 diabetes with lifestyle intervention or metformin. N. Engl. J. Med., 346: 393-403, 2002.

13- KWON H.R., HAN K.A., KU Y.H., AHN H.J., KOO B.K., KIM H.C. and MIN K.W.: The effects of resistance training on muscle and body fat mass and muscle strength in type 2 diabetic women. Korean Diabetes J., 34: 101-10, 2010.

14- DEKKER M.J., LEE S., HUDSON R., KILPATRICK K., GRAHAM T.E., ROSS R. and ROBINSON L.E. : An exercise intervention without weight loss decreases circulating interleukin- 6 in lean and obese men with and without type 2 diabetes mellitus. Metabolism Clinical and Experimental, 56: 332-8, 2007.

15- BROWN A.B., GREENBAUM L., SHTUKMASTER S., ZADOK Y., BEN-EZRA S. and KUSHKULEY L.: Characterization of non-thermal focused ultrasound for noninvasive selective fat cell disruption (lysis): Technical and preclinical assessment. Plastic and Reconstructive Surgery, 124: 92-101, 2009.

16- PALUMBO P., B. CINQUE, G. MICONI, C. La TORRE, G. ZOCCALI and M. GIULIANI: Biological effects of low frequency high intensity ultrasound application on ex vivo human adipose tissue. IPP, 24 (2): 411-22, 2011.
17- ASCHER B.: Safety and efficacy of ultra-shape contour I treatments to improve the appearance of body contours: Multiple treatments in shorter intervals. A.S.J., 30 (2): 217-24, 2010.

18- SABBOUR A., OMAR H., M, EL-BANNA A. and M.D. The Efficiency of Cavitation Ultrasound Therapy on Visceral Adiposity in Perimenpausal Women. Bull Fac. Ph. Th. Cairo Univ., 14 (1): 93-102, 2009.

19-TER-HAAR G. and COUSSIOS C.: High intensity focused ultrasound: Physical principle and devices. Hyperthermia, 23: 89-104, 2007.

20- GARCIA-MURRAY E., RIVAS O.A. and STECCO K.A.: "The use and mechanism of action of high intensity focused ultrasound for adipose tissue removal and noninvasive body sculpting". Presented at the American Society of Plastic Surgery Annual Meeting. Chicago (IL), September 28, 2005.

21- MORENO-MORAGA J., VALERO-ALTÉS T., RIQUELME A.M., ISARRIA-MARCOSY M.I. and De La TORRE J.R.: "Body contouring by non-invasive transdermal focused ultrasound.” Lasers Surg, Med., 39: 3 15-23, 2007.

22- NICKLAS B.J., ROGUS E.M., BERMAN D.M., DENNIS K.E. and GOLDBERG A.P.: Responses of adipose tissue lipoprotein lipase to weight loss affect lipid levels and weight regain in women. Am. J. Physiol. Endocrinol. Metab., 279 (5): E1 012-92000.

23- MARTIN B., RAYMOND D., TCHERNOF A., MATTHEWS D., ERNESTO G. and ERIC T.: Visceral Adipose Tissue Is Independent Correlate of Glucose Disposal in Older Obese Postmenopausal women. J. Clin. Endocrinol. Metab., 85: 2378-84, 2001.

24- TEITELBAUM S.A., BURNS J.L. and KUBOTA J. Noninvasive body contouring by focused ultrasound: Safety and efficacy of the Contour I device in a multicenter, controlled clinical study. Plast. Reconstr. Surgery, 120; (3): 779-89, 2007.

25- SHEK S., YU C. and YEUNG C.K. : The use of focused ultrasound for non-invasive body contouring in Asian. Lasers Surg. Med., 41: 751-9, 2009.

26- DESPRÉS J., LEMIEUX I. and PRUD'HOMME D.: Treatment of obesity: Need to focus on high risk abdominally obese patients. B.M.J., 24; 322 (7288): 716-72, 2001 .

27- ELLEN M., MICHAEL J., MARIE A., RICHARD D. and KIRK J.: Body composition changes with diet and exercise in obese women: A comparison of estimates from clinical methods and a 4-component model. Am. J. Clic. Nutr., 70: 5-12, 2000.

28- BERMAN D.M., NICKLAS B.J., RYAN A.S., ROGUS E.M., DENNIS K.E. and GOLDBERG A.B.: Regulation of lipolysis and lipoprotein lipase after weight loss in obese, postmenopausal women. Obesity research, 12 (1): 32-9, 2004.

29- TERESA KULIE, MD, ANDREW SLATTENGREN, DO, JACKIE REDMER MD, MPH, HELEN COUNTS, MD, ANNE EGLASH, MD, and SARINA SCHRAGER MD, 
MS.: Obesity and Women's Health: An Evidence-Based Review. J. Am. Board. Fam. Med., 24: 75-85, 2011.

30- SCOTT M. GRUNDY, H. BRYAN BREWER, JAMES

I. CLEEMAN, C. SMITH and CLAUDE LENFANT:

Definition of Metabolic Syndrome, Report of the National
Heart, Lung, and Blood Institute/American Heart Association Conference on Scientific Issues Related to Definition. Circulation, 109: 433-8, 2004.

31- BRAY G.A.: Risks of obesity. Endocrinol. Metab. Clin. N. Am., 32: 787-804, 2003.

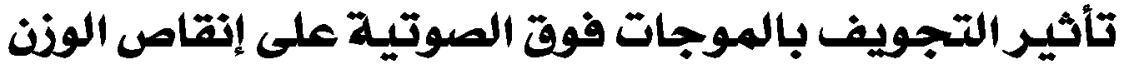

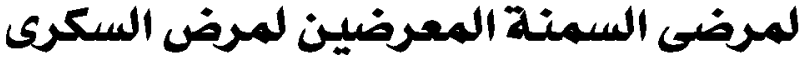

خلفية: تلقت السمنة إهتماما باهظا بإعتباره خطرا هحيا كبيرا ويمكن آن يكن السبب الكامن وداء العديد من الإضطرابات والآمراض من من

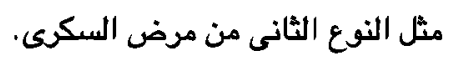

الهدف:دراسة لبحث تآثير التجويف بالموجات فوق الصوتية على آنقاض الوزن لمرضى السمنة المعرضين لمرض السكرى.

التصهيم: لدراسة تجريبية للتحكم العشوائى مع إستخدام مجموعة ضابطة.

الآشخاص: خمسعن مريضا إناثا من مرض السمنة ومعرضون لمرض السكرى. وقد قسمت عشوائيا إلى مجموعتين، Y0 مريضا فى كل

طريقة البحث: المجموعة الضعابطة (آ): 0ب مريضة تم علاجها بواسطة التمارين الرياضية والنظام الغذائى المتقانن المنففض في السعرات

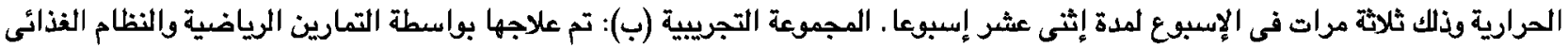

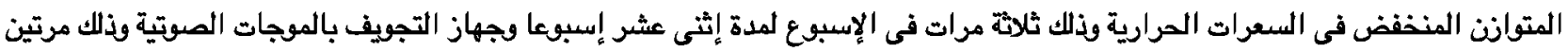

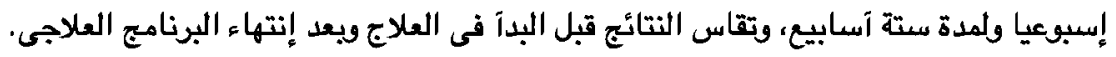

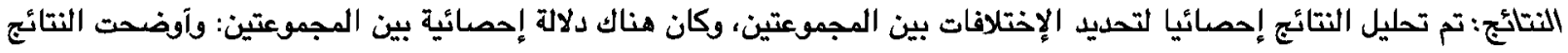

تصسن كبير في المجموعة (ب) آكثر في المجموعة (آ). وقد آوضحت إختبارات ذات دلالة إحصائية بين المجموعة (آ) والمجموعة (ب).

الخلاصدة: إضافة جهاز التجويف بالموجات الصوتية إلى النظام الفذائى المتوازن ذات السعرات المرارية المنففضة والتمارين الرياضية

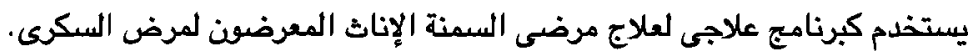

